\title{
Effects of canagliflozin on amputation risk in type 2 diabetes: the CANVAS Program
}

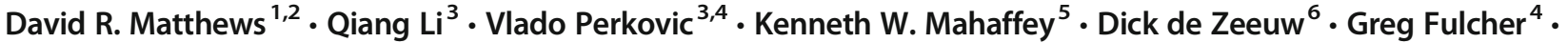 \\ Mehul Desai $^{7}$ - William R. Hiatt ${ }^{8} \cdot$ Mark Nehler $^{9}$. Elisa Fabbrini ${ }^{7} \cdot$ Mary Kavalam $^{7}$ - Mary Lee ${ }^{7}$. Bruce Neal ${ }^{3,10}$
}

Received: 15 October 2018 / Accepted: 28 January 2019 / Published online: 12 March 2019

(C) The Author(s) 2019

\begin{abstract}
Aims/hypothesis The primary analysis of the Canagliflozin cardioVascular Assessment Study (CANVAS) Program showed canagliflozin to have a beneficial effect on cardiovascular and renal outcomes in people with type 2 diabetes at high cardiovascular risk, but also an unexpected increased risk of major or minor lower extremity amputation. These secondary analyses explore this finding in more detail.

Methods The effect of canagliflozin on amputation risk in the CANVAS Program was calculated for amputations of different types and proximate aetiologies and different canagliflozin doses. Univariate and multivariate associations of baseline characteristics with amputation risk were determined and proportional and absolute effects of canagliflozin were compared across subgroups.

Results There were 187 (1.8\%) participants with atraumatic lower extremity amputations (minor 71\%, major 29\%); as previously published, rates were 6.30 vs 3.37 per 1000 participant-years with canagliflozin vs placebo (HR 1.97 [95\% CI 1.41, 2.75]). Risk was similar for ischaemic and infective aetiologies and for $100 \mathrm{mg}$ and $300 \mathrm{mg}$ doses. Overall amputation risk was strongly associated with baseline history of prior amputation (major or minor) (HR 21.31 [95\% CI 15.40, 29.49]) and other established risk factors. No interactions between randomised treatment and participant characteristics explained the effect of canagliflozin on amputation risk. For every clinical subgroup studied, numbers of amputation events projected were smaller than numbers of major adverse cardiovascular events averted.

Conclusions/interpretation The CANVAS Program demonstrated that canagliflozin increased the risk of amputation (mainly minor) in this study population. Anticipated risk factors for amputation were identified, such as prior history of amputation, peripheral vascular disease and neuropathy, but no specific aetiological mechanism or at-risk subgroup for canagliflozin was identified.
\end{abstract}

Keywords Clinical diabetes $\cdot$ Clinical science $\cdot$ Diabetic foot $\cdot$ Human $\cdot$ Oral pharmacological agents

A complete list of investigators in the CANVAS Program is provided in the electronic supplementary material (ESM) Appendix.

Electronic supplementary material The online version of this article (https://doi.org/10.1007/s00125-019-4839-8) contains peer-reviewed but unedited supplementary material, which is available to authorised users.

David R. Matthews

david.matthews@ocdem.ox.ac.uk

1 Oxford Centre for Diabetes, Endocrinology and Metabolism, University of Oxford, Oxford, UK

2 Harris Manchester College, University of Oxford, Mansfield Road, Oxford OX1 3TD, UK

3 The George Institute for Global Health, UNSW Sydney, Sydney, NSW, Australia

4 The Royal North Shore Hospital and University of Sydney, Sydney, NSW, Australia
5 Stanford Center for Clinical Research, Department of Medicine, Stanford University School of Medicine, Stanford, CA, USA

6 University Medical Center Groningen, University of Groningen, Groningen, the Netherlands

7 Janssen Research \& Development, LLC, Raritan, NJ, USA

8 Division of Cardiology and CPC Clinical Research, University of Colorado School of Medicine, Aurora, CO, USA

9 Division of Vascular Surgery and CPC Clinical Research, University of Colorado School of Medicine, Aurora, CO, USA

10 Epidemiology and Biostatistics, Imperial College London, London, UK 


\section{Research in context}

\section{What is already known about this subject?}

- The CANVAS Program identified an increased risk of amputation with canagliflozin vs placebo

- Of the other SGLT2 inhibitors currently marketed, ertugliflozin also carries a labelled warning of amputation risk but no comparable association was identified with empagliflozin. Observational analyses of the associations of SGLT2 inhibitor use with amputation are inconsistent

- There is no explanation for how SGLT2 inhibition might contribute to amputation risk or why this risk might vary between trial programmes

\section{What is the key question?}

- What is the cause of the amputation risk seen within the CANVAS Program?

\section{What are the new findings?}

- Analysing the published CANVAS Program finding of a 1.97-fold increased risk of amputation associated with canagliflozin use, we show the anticipated associations of risk factors with amputation, including prior history of amputation, peripheral vascular disease and neuropathy

- We identified no specific cause or mechanism for the increased amputation risk, nor any at-risk subgroup for canagliflozin

- The analyses excluded any strong interactions of canagliflozin with participant demographics, disease history or concurrent drug therapy and excluded any specific effect on amputation of ischaemic vs infective aetiology

\section{How might this impact on clinical practice in the foreseeable future?}

- Labelling advice regarding the discontinuation or avoidance of SGLT2 inhibitors by individuals at high risk for amputation is reasonable but may not fully ameliorate amputation risk. Nonetheless, most high-risk individuals will probably achieve net benefit with SGLT2 inhibitors because numbers of amputations caused are likely to be lower than the number of serious cardio-renal events averted

$\begin{array}{ll}\begin{array}{ll}\text { Abbreviations } \\ \text { CANVAS }\end{array} & \begin{array}{l}\text { Canagliflozin cardioVascular } \\ \text { Assessment Study }\end{array} \\ \text { CANVAS-R } & \text { CANVAS-Renal } \\ \text { GLP-1 } & \text { Glucagon-like peptide-1 } \\ \text { SGLT2 } & \text { Sodium-glucose cotransporter 2 }\end{array}$

\section{Introduction}

Canagliflozin is a sodium-glucose cotransporter 2 (SGLT2) inhibitor approved for the treatment of type 2 diabetes mellitus [1]. The Canagliflozin cardioVascular Assessment Study (CANVAS) Program [2] integrated data from two directly comparable, double-blind, randomised, placebo-controlled trials (CANVAS and CANVAS-Renal [CANVAS-R]; ClinicalTrials.gov registration no. NCT01032629, NCT01989754) [3, 4] involving participants with type 2 diabetes and a history or high risk of cardiovascular disease, conducted at 667 sites across 30 countries.
CANVAS was commenced in 2009 to demonstrate the cardiovascular safety of canagliflozin prior to registration, and CANVAS-R was commenced in 2014 as a post-registration commitment to regulatory agencies. The trials were designed to complete simultaneously when a prespecified minimum number of cardiovascular events (688) and a minimum follow-up time (78 weeks) were achieved; this occurred in late 2016 [5]. The CANVAS Program showed a beneficial effect of canagliflozin treatment on the primary outcome of major adverse cardiovascular events (HR 0.86 [95\% CI 0.75, 0.97], $p<0.001$ for non-inferiority, $p<0.02$ for superiority) [2].

An emergent finding of the CANVAS Program was an increased risk of lower extremity major and minor amputation in participants treated with canagliflozin compared with placebo (HR 1.97 [95\% CI 1.41, 2.75]) [2], where major atraumatic lower extremity amputations were defined as being at or above the ankle and minor as being atraumatic lower extremity amputations below the ankle. This safety signal was flagged to the Steering Committee in the final year of the trial by the Independent Data Monitoring Committee on 18 February 2016. Global health authorities, including those in Europe and the USA, were informed and responded with 
updates to the product information [6]. No prior clinical or preclinical study had raised any concern regarding limb perfusion or amputation, and the known tissue expression and actions of the SGLT isoforms provide no indication of the likely mechanism. Currently, of the seven marketed SGLT2 inhibitors, one other (ertugliflozin) also carries a labelled warning about amputation risk [7]. The objectives of this paper were to explore in more detail the effects of canagliflozin on amputation risk and to estimate likely risks and benefits for different participant subgroups.

\section{Methods}

Ethics CANVAS and CANVAS-R were approved by the ethics committees at each site and all participants provided written informed consent. All procedures followed were in accordance with the Helsinki Declaration of 1964, as revised in 2013.

Participants Participants were men and women with type 2 diabetes mellitus and $\mathrm{HbA}_{1 \mathrm{c}} \geq 53 \mathrm{mmol} / \mathrm{mol}(7.0 \%)$ and $\leq 91$ $\mathrm{mmol} / \mathrm{mol}(10.5 \%)$. They were $\geq 30$ years of age with a history of symptomatic atherosclerotic cardiovascular disease (which included prior amputation) or $\geq 50$ years of age with two or more of the following risk factors for cardiovascular disease: duration of diabetes $\geq 10$ years, systolic $\mathrm{BP}>140 \mathrm{mmHg}$ while on one or more antihypertensive agent, current smoker, microalbuminuria or macroalbuminuria or HDL-cholesterol $<1 \mathrm{mmol} / \mathrm{l}$ [2]. The presence of amputation or peripheral vascular disease history at baseline was based upon physician reporting with no requirement for specific clinical evaluation or imaging.

Randomised treatment All potential participants completed a 2 week, single-blind, placebo run-in period with subsequent randomisation of eligible participants done centrally using an interactive web response system and a computer-generated randomisation schedule. Participants in CANVAS were randomly assigned in a 1:1:1 ratio to receive canagliflozin $300 \mathrm{mg}$, canagliflozin $100 \mathrm{mg}$ or matching placebo, and participants in CANVAS-R were randomly assigned in a 1:1 ratio to receive canagliflozin or matching placebo (initially $100 \mathrm{mg}$ with optional uptitration to $300 \mathrm{mg}$ ).

Follow-up and data collection Face-to-face follow-up was scheduled for three visits in the first year and at 6 month intervals thereafter, with alternating telephone follow-up between face-to-face assessments. Every follow-up included inquiry about serious adverse events. Amputation events were initially recorded routinely by the investigators using electronic case record forms for the capture of adverse events and/or diagnostic and therapeutic procedures. In July 2016, following notification of the amputation safety signal, a dedicated case report form was created to ensure systematic and standardised data collection for amputation events. Investigators were directed to complete the amputation case report form for every new event, as well as retrospectively for every amputation event already recorded. Additionally, all CANVAS Program participant case records and the associated pharmacovigilance database were searched using the terms 'ampu', 'remov', 'resection', 'necrosectomy', 'disarticulation', 'exarticulation', 'BKA' and 'AKA' to identify any additional possible amputation events. Information collected included the date of the amputation and whether the amputation was traumatic or atraumatic, as well as the location (right or left, toes, trans-metatarsal, ankle, below knee or above knee, other). Amputation events occurring at any time point prior to final follow-up, for all randomised participants regardless of whether the participant remained on the study drug, were captured [2]. A secondary post hoc assessment of the proximate aetiologies underlying each amputation was made by a specialist in peripheral vascular disease (MN), using source documentation collected at the time of the event from the participating sites, to identify the presence of infection, chronic ischaemia or acute ischaemia.

Outcomes In these secondary analyses, the main outcome was all atraumatic lower extremity amputations, which were reported as all major atraumatic lower extremity amputations (at or above ankle) and all minor atraumatic lower extremity amputations (below ankle). Benefits were reported for the composite outcome of major adverse cardiovascular events comprising cardiovascular death, non-fatal stroke and nonfatal myocardial infarction.

Statistical methodology The impact of canagliflozin on amputation risk was assessed among the dosed participants using a Cox proportional hazard model with treatment as the possible explanatory variable and adjustment for trial (CANVAS or CANVAS-R). The treatment effect was expressed as the HR and $95 \% \mathrm{CI}$, with a test of proportional hazards used to examine the evolution of the treatment effect over time. Comparability of the effects of canagliflozin on amputation was examined for participant subgroups by fitting treatment interaction terms to the proportional hazards models. Analyses were performed on the integrated CANVAS Program dataset except for the investigation of dose effects, which were done in the CANVAS dataset alone (without CANVAS-R). Baseline participant characteristics associated with amputation risk were assessed using proportional hazards models in the CANVAS Program dataset. First, univariate associations were determined for candidate risk factors for amputation independent of treatment assignment and then those risks with significant univariate associations were included in a single multivariate model that also included randomised treatment. 
Table 1 Baseline characteristics of participants with and without major or minor amputation during follow-up ${ }^{\mathrm{a}}$

\begin{tabular}{|c|c|c|c|c|c|c|c|}
\hline \multirow[t]{2}{*}{ Characteristic } & \multicolumn{3}{|c|}{ Participants with amputation } & \multicolumn{3}{|c|}{ Participants without amputation } & \multirow{2}{*}{$\begin{array}{l}p \text { value } \\
\text { (total with } \\
\text { amputation vs } \\
\text { total without } \\
\text { amputation) }^{\mathrm{b}}\end{array}$} \\
\hline & $\begin{array}{l}\text { Canagliflozin } \\
(n=140)\end{array}$ & $\begin{array}{l}\text { Placebo } \\
(n=47)\end{array}$ & $\begin{array}{l}\text { Total } \\
(n=187)\end{array}$ & $\begin{array}{l}\text { Canagliflozin } \\
(n=5650)\end{array}$ & $\begin{array}{l}\text { Placebo } \\
(n=4297)\end{array}$ & $\begin{array}{l}\text { Total } \\
(n=9947)\end{array}$ & \\
\hline Age, years, mean (SD) & $62.3(7.1)$ & $60.9(6.3)$ & $62.0(6.9)$ & $63.2(8.3)$ & $63.5(8.2)$ & $63.3(8.3)$ & 0.025 \\
\hline Female sex, $n(\%)$ & $27(19.3)$ & $5(10.6)$ & $32(17.1)$ & $2007(35.5)$ & $1592(37.0)$ & $3599(36.2)$ & $<0.001$ \\
\hline Race, $n(\%)$ & & & & & & & 0.008 \\
\hline White & $120(85.7)$ & $44(93.6)$ & $164(87.7)$ & 4385 (77.6) & 3389 (78.9) & 7774 (78.2) & \\
\hline Asian & $8(5.7)$ & $2(4.3)$ & $10(5.3)$ & $769(13.6)$ & $505(11.7)$ & $1274(12.8)$ & \\
\hline Black or African-American & $2(1.4)$ & $1(2.1)$ & $3(1.6)$ & $173(3.1)$ & $159(3.7)$ & $332(3.3)$ & \\
\hline Other $^{c}$ & $10(7.1)$ & $0(0.0)$ & $10(5.3)$ & $323(5.7)$ & $244(5.7)$ & $567(5.7)$ & \\
\hline Current smoker, $n(\%)$ & $22(15.7)$ & $14(29.8)$ & $36(19.3)$ & $996(17.6)$ & $770(17.9)$ & $1766(17.8)$ & 0.597 \\
\hline History of hypertension, $n(\%)$ & $123(87.9)$ & $42(89.4)$ & $165(88.2)$ & $5060(89.6)$ & 3893 (90.6) & $8953(90.0)$ & 0.424 \\
\hline $\begin{array}{l}\text { Duration of diabetes, years, } \\
\text { mean (SD) }\end{array}$ & $16.8(8.6)$ & $14.8(8.4)$ & $16.3(8.6)$ & $13.4(7.7)$ & $13.7(7.8)$ & $13.5(7.7)$ & $<0.001$ \\
\hline \multicolumn{8}{|l|}{ Microvascular disease history, $n(\%)$} \\
\hline Nephropathy & $40(28.6)$ & $16(34.0)$ & $56(29.9)$ & $953(16.9)$ & $763(17.8)$ & $1716(17.3)$ & $<0.001$ \\
\hline Retinopathy & $50(35.7)$ & $19(40.4)$ & $69(36.9)$ & $1152(20.4)$ & $906(21.1)$ & $2058(20.7)$ & $<0.001$ \\
\hline Neuropathy & $84(60.0)$ & $27(57.4)$ & $111(59.4)$ & $1703(30.1)$ & $1295(30.1)$ & $2998(30.1)$ & $<0.001$ \\
\hline \multicolumn{8}{|l|}{ Atherosclerotic disease, $n(\%)^{\mathrm{d}}$} \\
\hline Coronary & $83(59.3)$ & $28(59.6)$ & $111(59.4)$ & $3148(55.7)$ & $2458(57.2)$ & $5606(56.4)$ & 0.413 \\
\hline Cerebrovascular & $35(25.0)$ & $10(21.3)$ & $45(24.1)$ & $1076(19.0)$ & $835(19.4)$ & $1911(19.2)$ & 0.111 \\
\hline Peripheral & $81(57.9)$ & $32(68.1)$ & $113(60.4)$ & $1094(19.4)$ & $904(21.0)$ & $1998(20.1)$ & $<0.001$ \\
\hline Any & $129(92.1)$ & $43(91.5)$ & $172(92.0)$ & 3994 (70.7) & $3152(73.4)$ & $7146(71.8)$ & $<0.001$ \\
\hline $\begin{array}{l}\text { History of cardiovascular } \\
\quad \text { disease, } n(\%)^{\mathrm{e}}\end{array}$ & $116(82.9)$ & $38(80.9)$ & $154(82.4)$ & $3636(64.4)$ & $2861(66.6)$ & $6497(65.3)$ & $<0.001$ \\
\hline History of atrial fibrillation, $n(\%)$ & $12(8.6)$ & $6(12.8)$ & $18(9.6)$ & $339(6.0)$ & $256(6.0)$ & $595(6.0)$ & 0.038 \\
\hline History of heart failure, $n(\%)$ & $27(19.3)$ & $8(17.0)$ & $35(18.7)$ & $774(13.7)$ & $650(15.1)$ & $1424(14.3)$ & 0.093 \\
\hline History of amputation, $n(\%)$ & $38(27.1)$ & $13(27.7)$ & $51(27.3)$ & $98(1.7)$ & $88(2.0)$ & $186(1.9)$ & $<0.001$ \\
\hline BMI, kg/m², mean (SD) & $32.5(5.9)$ & $33.3(6.9)$ & $32.7(6.1)$ & $31.9(5.9)$ & $32.0(5.9)$ & $31.9(5.9)$ & 0.0765 \\
\hline Systolic BP, mmHg, mean (SD) & $138.5(16.4)$ & $135.0(15.7)$ & $137.6(16.3)$ & $136.4(15.8)$ & $136.9(15.8)$ & $136.6(15.8)$ & 0.3947 \\
\hline Diastolic BP, mmHg, mean (SD) & $77.3(9.4)$ & $78.0(10.1)$ & $77.5(9.6)$ & $77.6(9.6)$ & $77.8(9.7)$ & $77.7(9.7)$ & 0.7711 \\
\hline $\mathrm{HbA}_{1 \mathrm{c}}, \mathrm{mmol} / \mathrm{mol}$, mean (SD) & $69(9.8)$ & $68(10.9)$ & $69(9.8)$ & $66(9.8)$ & $66(9.8)$ & $66(9.8)$ & $<0.001$ \\
\hline $\mathrm{HbA}_{1 \mathrm{c}}, \%$, mean $(\mathrm{SD})$ & $8.5(0.9)$ & $8.4(1.0)$ & $8.5(0.9)$ & $8.2(0.9)$ & $8.2(0.9)$ & $8.2(0.9)$ & $<0.001$ \\
\hline LDL-cholesterol, mmol/l, mean (SD) & $2.3(1.0)$ & $2.5(0.9)$ & $2.4(1.0)$ & $2.3(0.9)$ & $2.3(0.9)$ & $2.3(0.9)$ & 0.3481 \\
\hline $\begin{array}{l}\text { LDL/HDL-cholesterol ratio, } \\
\text { mean (SD) }\end{array}$ & $2.1(1.0)$ & $2.3(0.8)$ & $2.1(0.9)$ & $2.0(0.9)$ & $2.0(0.9)$ & $2.0(0.9)$ & 0.1537 \\
\hline $\begin{array}{l}\text { eGFR, } \mathrm{ml} \mathrm{min}^{-1}[1.73 \mathrm{~m}]^{-2} \\
\text { mean }(\mathrm{SD})^{\mathrm{f}}\end{array}$ & $72.4(18.2)$ & $73.7(23.5)$ & $72.7(19.7)$ & $76.8(20.3)$ & $76.2(20.8)$ & $76.5(20.5)$ & 0.0121 \\
\hline Micro- or macroalbuminuria, $n(\%)^{\mathrm{g}}$ & $69(49.6)$ & $26(56.5)$ & $95(51.4)$ & $1656(29.6)$ & $1272(30.0)$ & $2928(29.7)$ & $<0.001$ \\
\hline \multicolumn{8}{|l|}{ Concomitant drug therapies, $n(\%)$} \\
\hline Insulin & $96(68.6)$ & $35(74.5)$ & $131(70.1)$ & $2793(49.4)$ & $2169(50.5)$ & $4962(49.9)$ & $<0.001$ \\
\hline Metformin & $92(65.7)$ & $37(78.7)$ & $129(69.0)$ & $4351(77.0)$ & $3340(77.7)$ & $7691(77.3)$ & 0.0071 \\
\hline Sulfonylurea & $51(36.4)$ & $18(38.3)$ & $69(36.9)$ & $2475(43.8)$ & $1815(42.2)$ & $4290(43.1)$ & 0.0882 \\
\hline GLP-1 receptor agonist & $8(5.7)$ & $2(4.3)$ & $10(5.3)$ & $214(3.8)$ & $183(4.3)$ & $397(4.0)$ & 0.3493 \\
\hline DPP-4 inhibitor & $12(8.6)$ & $5(10.6)$ & $17(9.1)$ & $685(12.1)$ & $559(13.0)$ & $1244(12.5)$ & 0.1610 \\
\hline Loop diuretic & $33(23.6)$ & $8(17.0)$ & 41 (21.9) & $683(12.1)$ & $584(13.6)$ & 1267 (12.7) & 0.0002 \\
\hline Non-loop diuretic & $53(37.9)$ & $17(36.2)$ & $70(37.4)$ & $2030(35.9)$ & $1546(36.0)$ & $3576(36.0)$ & 0.6756 \\
\hline Calcium antagonist & $52(37.1)$ & $17(36.2)$ & $69(36.9)$ & $1878(33.2)$ & $1496(34.8)$ & 3374 (33.9) & 0.3942 \\
\hline RAAS inhibitor & $112(80.0)$ & $36(76.6)$ & $148(79.1)$ & $4530(80.2)$ & 3435 (79.9) & $7965(80.1)$ & 0.7525 \\
\hline$\beta$-Blocker & $79(56.4)$ & $30(63.8)$ & $109(58.3)$ & $2959(52.4)$ & $2352(54.7)$ & $5311(53.4)$ & 0.1836 \\
\hline
\end{tabular}


Table 1 (continued)

\begin{tabular}{|c|c|c|c|c|c|c|c|}
\hline \multirow[t]{2}{*}{ Characteristic } & \multicolumn{3}{|c|}{ Participants with amputation } & \multicolumn{3}{|c|}{ Participants without amputation } & \multirow{2}{*}{$\begin{array}{l}p \text { value } \\
\text { (total with } \\
\text { amputation vs } \\
\text { total without } \\
\text { amputation) }^{\mathrm{b}}\end{array}$} \\
\hline & $\begin{array}{l}\text { Canagliflozin } \\
(n=140)\end{array}$ & $\begin{array}{l}\text { Placebo } \\
(n=47)\end{array}$ & $\begin{array}{l}\text { Total } \\
(n=187)\end{array}$ & $\begin{array}{l}\text { Canagliflozin } \\
(n=5650)\end{array}$ & $\begin{array}{l}\text { Placebo } \\
(n=4297)\end{array}$ & $\begin{array}{l}\text { Total } \\
(n=9947)\end{array}$ & \\
\hline Statin & $102(72.9)$ & $35(74.5)$ & $137(73.3)$ & $4224(74.8)$ & $3235(75.3)$ & $7459(75.0)$ & 0.5895 \\
\hline Aspirin & $67(47.9)$ & $20(42.6)$ & $87(46.5)$ & $1884(33.3)$ & $978(22.8)$ & $2862(28.8)$ & $<0.001$ \\
\hline Other antithrombotic & $41(29.3)$ & $24(51.1)$ & $65(34.8)$ & $2240(39.6)$ & $2213(51.5)$ & $4453(44.8)$ & 0.006 \\
\hline
\end{tabular}

${ }^{a}$ One participant was randomised at two different sites and only the first randomisation is included in the intention-to-treat analysis set

${ }^{\mathrm{b}}$ Analysed with a Wilcoxon two-sample test

${ }^{\mathrm{c}}$ Includes American Indian or Alaska Native, Native Hawaiian or other Pacific Islander, multiple, other and unknown

${ }^{\mathrm{d}}$ Some participants had $>1$ type of atherosclerotic disease

e As defined in the protocol

${ }^{\mathrm{f}}$ Values for eGFR categories calculated based on $N$ of 5794 for canagliflozin, 4346 for placebo and 10,140 for the total population

${ }^{g}$ Values for albuminuria categories calculated based on $N$ of 5740 for canagliflozin, 4293 for placebo and 10,033 for the total population

DPP-4, dipeptidyl pepdidase-4; RAAS, renin-angiotensin-aldosterone system

Where a single risk was assessed using multiple measures (e.g. glucose and $\mathrm{HbA}_{1 \mathrm{c}}$ ), the risk with the greatest HR was carried forward for inclusion in the multivariate modelling. Absolute effects on all amputation, major amputation and major adverse cardiovascular events were modelled to estimate effects for 1000 participants treated for 5 years. This was done overall and for participant subsets defined by excluding participants with one or more of the risks for amputation that were significant in the multivariate modelling. The absolute effects on amputation and major adverse cardiovascular events were derived using the summary estimates of RRs derived from the CANVAS Program for each outcome applied to the absolute event rates specific to each subset of participants. All analyses were performed using SAS version 9.2 (SAS Institute, Cary, NC, USA), SAS Enterprise Guide version 7.1 (SAS Institute) and STATA version 13.1 (StataCorp, College Station, TX, USA).

\section{Results}

The CANVAS Program randomised 10,142 participants (CANVAS $[n=4330]$ and CANVAS-R $[n=5812]$ ) [3], of which 10,134 received at least one dose of randomised treatment. The mean follow-up of participants was 188 weeks (296 weeks in CANVAS and 108 weeks in CANVAS-R) [2]. Overall, the mean age of participants was 63.3 years, $35.8 \%$ were women, mean duration of diabetes was 13.5 years and $65.6 \%$ had a history of cardiovascular disease at baseline. Two hundred and thirty-eight (2\%) participants had a history of major or minor amputation at baseline and 187 (1.8\%) had one or more major or minor amputation events during follow-up. In total, 290 amputation events were recorded among these 187 participants during follow-up.

Associations of baseline participant characteristics with amputation risk At trial commencement, participants who had major or minor amputation during follow-up differed from participants who did not go on to have amputation during the trial (Table 1). Univariate modelling identified more than 20 baseline characteristics that were associated with amputation risk, eight of which (male sex, non-Asian ethnicity, prior amputation, peripheral vascular disease, neuropathy, albuminuria, higher $\mathrm{HbA}_{1 \mathrm{c}}$ and random allocation to canagliflozin) remained significant in multivariate modelling (Table 2).

Proximate aetiology of amputation Among the 187 participants who underwent a post-randomisation amputation, infection was identified as a proximate aetiology in most events: $136 / 140(97 \%)$ on canagliflozin and 47/47 (100\%) on placebo. About two-thirds also had chronic ischaemia: $82 / 140$ $(59 \%)$ on canagliflozin and $31 / 47(66 \%)$ placebo. Only $2 / 140(1.4 \%)$ canagliflozin-treated cases had an acute ischaemic aetiology recorded. Of the 187 participants experiencing amputation, $140(75 \%)$ were using randomised treatment at the time of amputation, 19 (10\%) had amputations within 30 days after discontinuation of randomised treatment and $28(15 \%)$ had amputations more than 30 days after discontinuation of randomised treatment.

Effects of canagliflozin on the risk of amputation Major or minor amputation events occurred in 47 of 4344 participants treated with placebo and 140 of 5790 participants treated with canagliflozin. The corresponding rates of major or minor amputation events were 3.37 and 6.30 events per 1000 
Table 2 Association of baseline participant characteristics with risk of major or minor amputation in univariate and multivariate models

\begin{tabular}{|c|c|c|}
\hline Characteristic & Univariate & Multivariate \\
\hline \multicolumn{3}{|l|}{ Demographics } \\
\hline Male sex & $2.63(1.80,3.85)$ & \multirow[t]{3}{*}{$2.26(1.53,3.35)$} \\
\hline Age (year older) & $0.98(0.97,1.00)$ & \\
\hline Current smoker & $1.11(0.77,1.59)$ & \\
\hline \multicolumn{3}{|l|}{ Race } \\
\hline White vs non-white & $2.18(1.41,3.38)$ & \multirow{3}{*}{$0.44(0.23,0.85)$} \\
\hline Asian vs non-Asian & $0.32(0.17,0.61)$ & \\
\hline Black vs non-Black & $0.59(0.19,1.86)$ & \\
\hline \multicolumn{3}{|l|}{ Region } \\
\hline North America vs others & $1.07(0.77,1.48)$ & \\
\hline Central/South America vs others & $1.64(1.03,2.62)$ & \\
\hline Europe vs others & $1.13(0.84,1.52)$ & \\
\hline Rest of world vs others & $0.68(0.49,0.94)$ & \\
\hline Prior amputation (Yes/No) & $21.31(15.40,29.49)$ & \multirow{3}{*}{$\begin{array}{c}16.27(10.65,24.63 \\
2.77(1.93,3.96)\end{array}$} \\
\hline Peripheral vascular disease $(\mathrm{Yes} / \mathrm{No})^{\mathrm{a}}$ & $2.51(1.85,3.41)$ & \\
\hline Cardiovascular disease (Yes/No) & $2.85(1.95,4.16)$ & \\
\hline \multicolumn{3}{|l|}{ Microvascular disease history } \\
\hline Neuropathy (Yes/No) & $3.38(2.52,4.52)$ & \multirow[t]{2}{*}{$1.86(1.35,2.56)$} \\
\hline Nephropathy (Yes/No) & $2.18(1.60,2.99)$ & \\
\hline Retinopathy (Yes/No) & $2.27(1.69,3.06)$ & \multirow{5}{*}{$1.63(1.20,2.22)$} \\
\hline Any albuminuria (Yes/No) & $2.65(1.99,3.54)$ & \\
\hline Hypertension $($ Yes/No) & $0.91(0.58,1.42)$ & \\
\hline Heart failure (Yes/No) & $1.52(1.05,2.19)$ & \\
\hline Duration of diabetes (year greater) & $1.04(1.03,1.06)$ & \\
\hline \multicolumn{3}{|l|}{ Concomitant medications (Yes/No) } \\
\hline Insulin use & $2.37(1.73,3.24)$ & \\
\hline Sulfonylurea & $0.72(0.53,0.97)$ & \\
\hline Metformin & $0.68(0.50,0.93)$ & \\
\hline GLP-1 receptor agonist & $1.59(0.84,3.03)$ & \\
\hline DPP-4 inhibitor & $0.83(0.50,1.37)$ & \\
\hline Loop diuretic & $1.26(0.95,1.68)$ & \\
\hline Non-loop diuretic & $1.04(0.77,1.40)$ & \\
\hline Statin & $0.94(0.68,1.30)$ & \\
\hline Aspirin & $1.34(0.89,2.03)$ & \\
\hline Other antithrombotic & $1.70(1.04,2.80)$ & \\
\hline RAAS inhibitor & $0.93(0.66,1.33)$ & \\
\hline$\beta$-Blocker & $1.28(0.96,1.71)$ & \\
\hline Calcium channel blocker & $1.17(0.87,1.57)$ & \\
\hline \multicolumn{3}{|l|}{ Laboratory and clinical variables } \\
\hline $\mathrm{HbA}_{1 \mathrm{c}}(10.9 \mathrm{mmol} / \mathrm{mol}[1 \%]$ greater $)$ & $1.37(1.18,1.58)$ & \multirow{10}{*}{$1.99(1.43,2.76)$} \\
\hline $\mathrm{HbA}_{1 \mathrm{c}}(\geq 64 \mathrm{mmol} / \mathrm{mol}[8 \%] \mathrm{vs}<64 \mathrm{mmol} / \mathrm{mol}[8 \%])$ & $2.12(1.54,2.93)$ & \\
\hline Haemoglobin $(1 \mathrm{~g} / 1$ greater $)$ & $1.00(0.99,1.01)$ & \\
\hline eGFR $(1 \mathrm{ml} / \mathrm{min}$ greater $)$ & $0.99(0.98,1.00)$ & \\
\hline Systolic BP (1 mmHg greater) & $1.00(1.00,1.01)$ & \\
\hline Haematocrit ( $1 \%$ greater) & $1.00(0.97,1.04)$ & \\
\hline BMI $\left(1 \mathrm{~kg} / \mathrm{m}^{2}\right.$ greater $)$ & $1.02(1.00,1.04)$ & \\
\hline LDL-cholesterol ( $0.026 \mathrm{mmol} / \mathrm{l}$ greater $)$ & $1.08(0.93,1.26)$ & \\
\hline HDL-cholesterol ( $0.026 \mathrm{mmol} / \mathrm{l}$ greater $)$ & $0.74(0.45,1.19)$ & \\
\hline Triacylglycerols $(0.011 \mathrm{mmol} / 1$ greater $)$ & $1.07(1.00,1.15)$ & \\
\hline Canagliflozin treatment & $1.97(1.41,2.75)$ & $1.82(1.29,2.56)$ \\
\hline
\end{tabular}

Data are shown as HR $(95 \% \mathrm{CI})$

The multivariate model included all characteristics with significant univariate associations. Only characteristics significant in the multivariate model are listed

${ }^{\text {a }}$ Excluding history of amputation

DPP-4, dipeptidyl peptidase-4; RAAS, renin-angiotensin-aldosterone system participant-years and the HR was 1.97 (95\% CI 1.41, 2.75) (Figs 1 and 2). The difference in the risk of amputation events between randomised groups evolved progressively throughout the study (test for proportional hazards $p=0.88$ ), with similar patterns of accrual observed for total, major and minor amputations (Fig. 2). There was no evidence that the effects of canagliflozin on amputation risk varied according to any baseline participant characteristic (all $p$ homogeneity $>0.123$ ). A possible exception was use of antithrombotic therapy, where the effects of canagliflozin compared with placebo were conventionally significantly greater among those not using such treatment $(p=0.0268)$. However, considering that small 
numbers were involved and that 25 interactions were tested, it is highly likely that one or more would meet the criterion for significance based on chance alone (Fig. 3).

Of the amputations recorded, $71 \%$ were minor and $29 \%$ major. There were no differences in proportional effects on the risks of minor vs major amputation (Fig. 1). The $100 \mathrm{mg}$ and $300 \mathrm{mg}$ doses of canagliflozin had similar effects on amputation risk compared with placebo in the CANVAS participants who were randomised between doses. The majority of participants who experienced amputation had a single event recorded $(n=123)$, and proportional effects of canagliflozin vs placebo on amputation risk were comparable with those experiencing more than one amputation event $(n=64)$. There were multiple amputations at varying locations on the same limb in $22 \%$ of participants assigned canagliflozin and $19 \%$ of participants assigned placebo and amputations at varying locations in both limbs for $13 \%$ of participants assigned canagliflozin and $17 \%$ of participants assigned placebo.

Risk of amputation and protection against major adverse cardiovascular events in participant groups without baseline risks for amputation Among the overall CANVAS population, there were four $(95 \%$ CI 1,8$)$ more major amputations among every 1000 participants treated for 5 years with canagliflozin compared with placebo and 15 (95\% CI 8, 22) more amputations in total (major or minor) (Table 3). There were 23 fewer major adverse cardiovascular events among every 1000 participants treated for 5 years $(95 \%$ CI 4, 42). The estimated numbers of excess amputations with canagliflozin compared with placebo were lower for major and all amputations among most participant subsets where there were baseline risks for amputation identified from the multivariate modelling (male sex, non-Asian ethnicity, prior amputation peripheral vascular disease, neuropathy, albuminuria and higher $\mathrm{HbA}_{1 \mathrm{c}}$ ) (Table 3). The estimated absolute reductions in major adverse cardiovascular events were also lower in those taking canagliflozin compared with placebo in most of these participant subsets. The same pattern of greater and lesser numbers of events with canagliflozin compared with placebo was also apparent for participant subsets derived by exclusions based upon combinations of the identified baseline risks for amputation (Table 3).

\section{Discussion}

We have previously reported the main outcomes of the CANVAS Program, which identified protective effects of canagliflozin against cardiovascular and renal outcomes but also demonstrated an increased risk of major and minor amputation [2]. This paper reports on our investigation of possible explanatory aetiological factors related to the excess amputation rate seen for both minor and major amputations. Overall, the absolute risk of major amputation was low and was offset by improvements in cardiovascular outcomes. Minor amputation, defined as surgery below the ankle, was more than twice as common relative to major amputation (at or above the ankle) but was also offset by the cardiovascular benefits. Neither a proximate aetiology nor an explicit risk category for the excess risk of amputation with canagliflozin compared with placebo could be defined. The excess risk was found across all examined categories.

Identified independent predictors of amputation within the CANVAS Program were a prior history of amputation, male sex, race, history of peripheral vascular disease, history of neuropathy, albuminuria and higher
Fig. 1 Risk of amputation with canagliflozin compared with placebo, overall, based on the highest level of amputation, according to each dose of canagliflozin or presumed aetiology. ${ }^{\mathrm{a} B}$ Based on CANVAS data alone

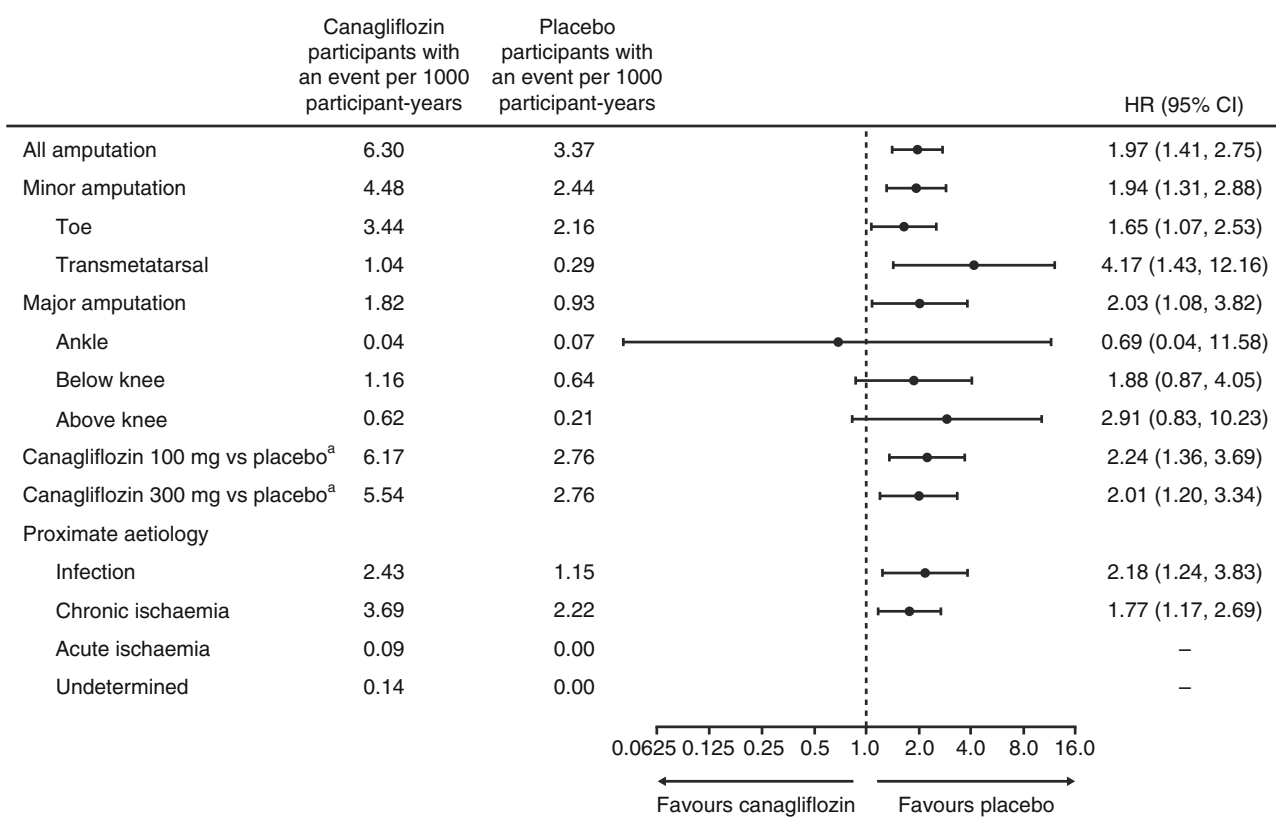


Fig. 2. Effects of canagliflozin compared with placebo on the risk of any amputation (a), major amputation (b) and minor amputation (c) pre-randomisation levels of $\mathrm{HbA}_{1 \mathrm{c}}$ in addition to treatment with canagliflozin. Of these, the highest risk was prior amputation, which we show carries an estimated

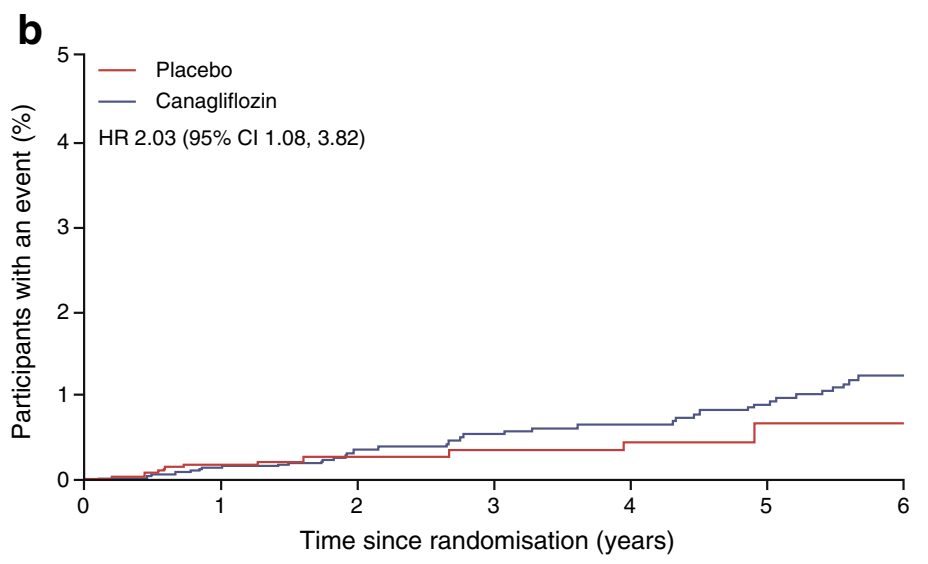

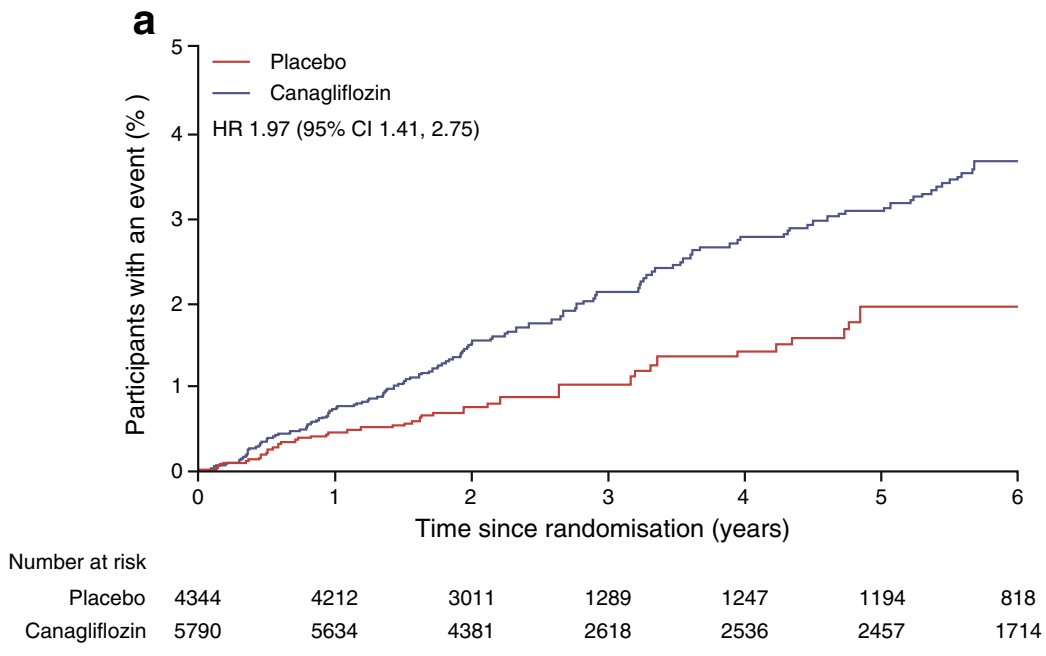

\begin{tabular}{|c|c|c|c|c|c|c|c|}
\hline Placebo & 4344 & 4224 & 3023 & 1296 & 1257 & 1206 & 827 \\
\hline Canagliflozin & 5790 & 5665 & 4426 & 2658 & 2590 & 2510 & 1756 \\
\hline
\end{tabular}

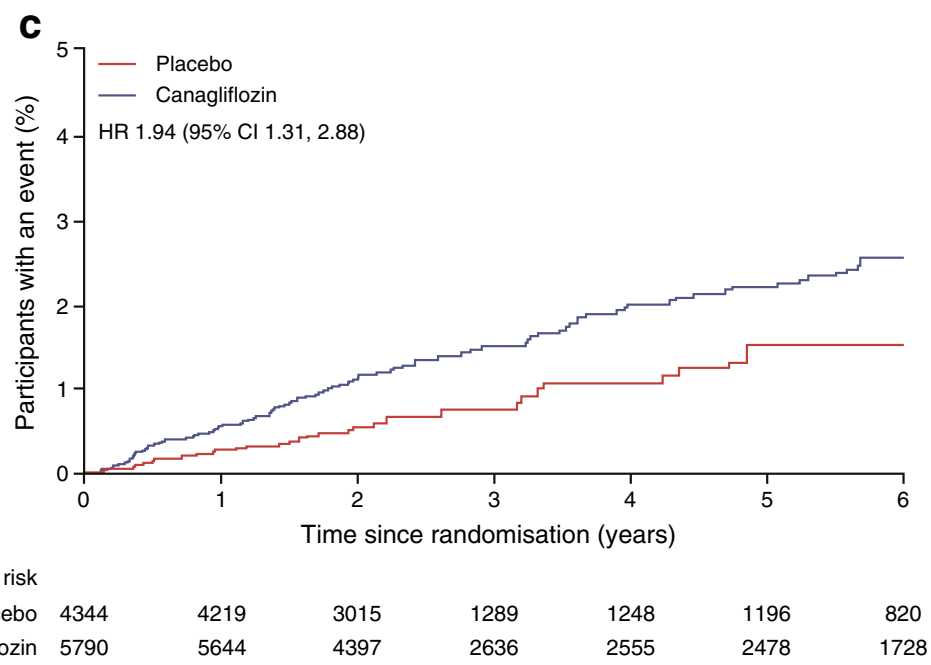

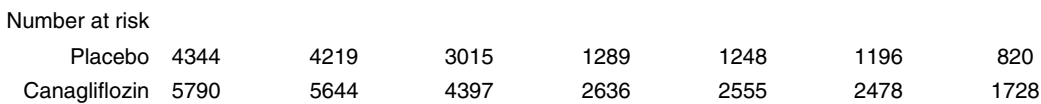

21.31-fold risk using univariate modelling and an estimated 16.27-fold risk using multivariate analyses. This compares with canagliflozin use yielding a 1.97-fold 
Fig. 3. Risk of amputation with canagliflozin compared with placebo in participant subgroups. $\mathrm{CV}$, cardiovascular; DPP-4, dipeptidyl peptidase-4; PVD, peripheral vascular disease; RAAS, renin-angiotensinaldosterone system

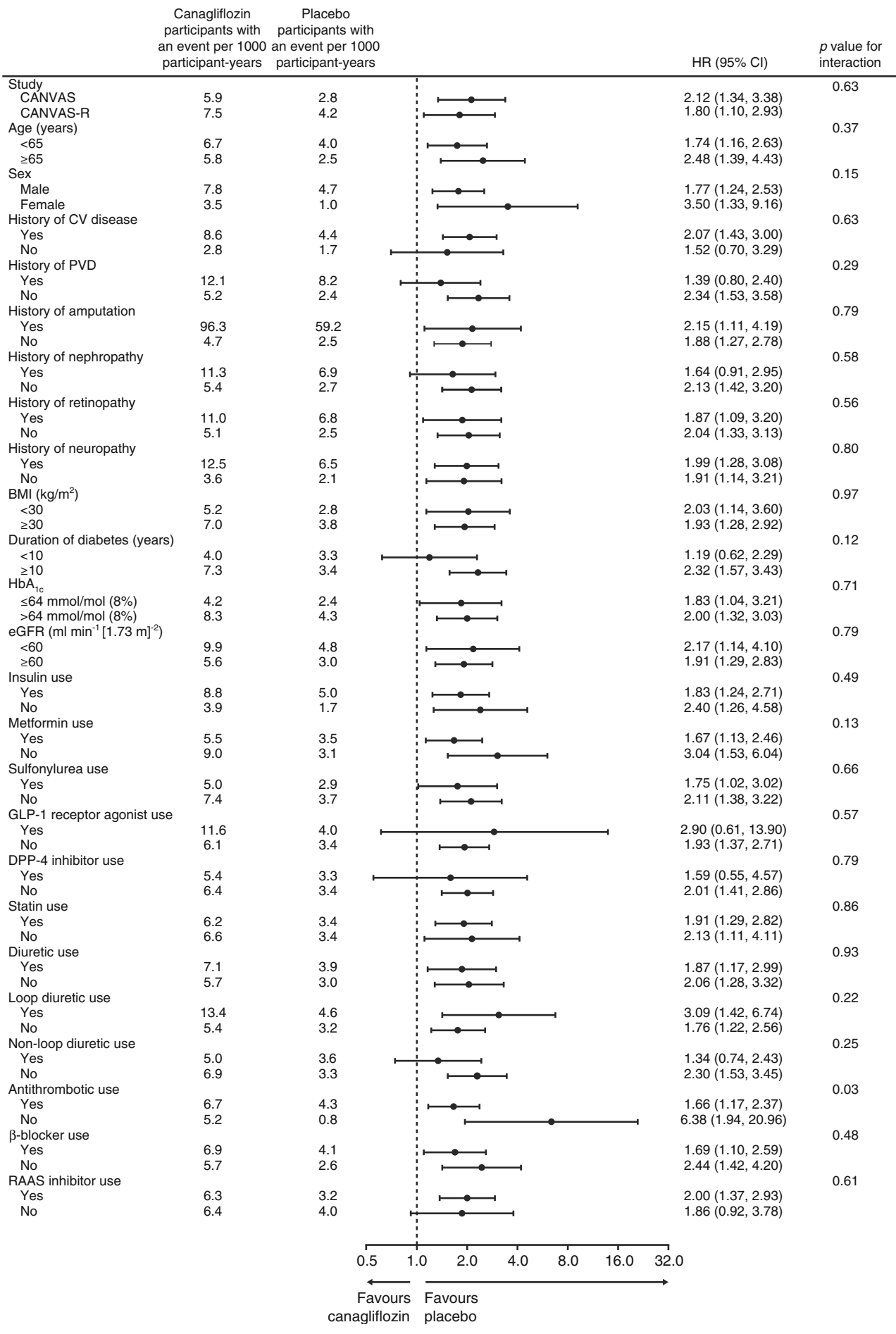

identify the subset of CANVAS participants who had amputation events, and it was not possible to further specify which individuals would achieve the optimal balance of benefit and risk with canagliflozin treatment. Existing recommendations pertaining to the careful monitoring of individuals with a higher risk for amputation events and provision of counselling about the importance of routine preventative foot care stand, as does advice regarding the possible discontinuation of canagliflozin 
Table 3 Numbers of major or minor amputations and major adverse cardiovascular events for every 1000 participants treated for 5 years, overall, and after exclusion of participant subsets with risks for amputation

\begin{tabular}{|c|c|c|c|c|c|c|}
\hline \multirow[t]{2}{*}{ Risk factor } & \multirow[t]{2}{*}{$\begin{array}{l}\text { Participants } \\
\text { excluded } \\
n(\%)\end{array}$} & \multicolumn{2}{|c|}{$\begin{array}{l}\text { Participants with } \\
\text { an amputation } \\
n \text { events per } \\
1000 \text { participant-years }\end{array}$} & \multicolumn{2}{|c|}{$\begin{array}{l}\text { Amputations among } \\
1000 \text { participants } \\
\text { treated for } 5 \text { years } \\
n(95 \% \mathrm{CI})\end{array}$} & \multirow{2}{*}{$\begin{array}{l}\text { Major adverse } \\
\text { cardiovascular } \\
\text { events prevented among } \\
1000 \text { participants treated } \\
\text { for } 5 \text { years } \\
n(95 \% \mathrm{CI})\end{array}$} \\
\hline & & Canagliflozin & Placebo & All & Major & \\
\hline All participants & $0(0)$ & 6.3 & 3.4 & $15(8,22)$ & $4(1,8)$ & $23(4,41)$ \\
\hline \multicolumn{7}{|c|}{ Excluding those with baseline risks identified as independent in multivariate modelling } \\
\hline Amputation & $237(2)$ & 4.7 & 2.5 & $11(5,17)$ & $5(2,8)$ & $21(3,40)$ \\
\hline Macroalbuminuria & $865(9)$ & 5.5 & 2.9 & $13(6,20)$ & $4(1,8)$ & $17(-2,35)$ \\
\hline Male sex & $6503(64)$ & 3.5 & 1.0 & $13(5,20)$ & $4(-1,9)$ & $17(-11,45)$ \\
\hline Non-Asian ethnicity & $8850(87)$ & 2.3 & 1.0 & $6(-4,17)$ & $4(-1,9)$ & $-2(-39,36)$ \\
\hline $\mathrm{PVD}^{\mathrm{a}}$ & $1874(18)$ & 5.2 & 2.4 & $14(7,21)$ & $3(-1,7)$ & $19(0,39)$ \\
\hline Neuropathy & $3109(31)$ & 3.6 & 2.0 & $8(1,14)$ & $3(-1,6)$ & $28(7,49)$ \\
\hline $\mathrm{HbA}_{1 \mathrm{c}} \geq 64 \mathrm{mmol} / \mathrm{mol}(8 \%)$ & $5729(57)$ & 3.6 & 2.5 & $5(-3,14)$ & $3(-2,7)$ & $11(-14,37)$ \\
\hline \multicolumn{7}{|l|}{ Excluding those with baseline risk combinations } \\
\hline Amputation or macroalbuminuria & $937(9)$ & 4.2 & 2.3 & $10(4,16)$ & $5(2,8)$ & $15(-4,33)$ \\
\hline PVD or macroalbuminuria & $2467(24)$ & 4.5 & 2.0 & $13(6,19)$ & $3(-1,6)$ & $13(-7,33)$ \\
\hline Amputation or PVD & $2111(21)$ & 3.2 & 1.3 & $10(4,15)$ & $3(0,6)$ & $17(-2,37)$ \\
\hline Neuropathy or macroalbuminuria & $3588(35)$ & 3.1 & 1.4 & $8(2,14)$ & $3(0,7)$ & $12(0,24)$ \\
\hline Amputation or neuropathy & $3211(32)$ & 2.7 & 1.6 & $6(0,12)$ & $3(0,6)$ & $26(5,47)$ \\
\hline PVD or neuropathy & $4037(40)$ & 3.0 & 1.2 & $9(3,15)$ & $2(-1,4)$ & $23(1,44)$ \\
\hline Amputation, PVD or macroalbuminuria & $2644(26)$ & 2.9 & 1.2 & $9(3,14)$ & $3(0,6)$ & $11(-8,310)$ \\
\hline Amputation, neuropathy or macroalbuminuria & $3664(36)$ & 2.3 & 1.3 & $5(0,10)$ & $3(0,6)$ & $19(-2,40)$ \\
\hline PVD, neuropathy or macroalbuminuria & $4438(44)$ & 2.5 & 0.7 & $9(4,14)$ & $2(0,5)$ & $18(-4,39)$ \\
\hline Amputation, PVD or neuropathy & $4139(41)$ & 2.0 & 0.6 & $7(2,12)$ & $2(0,4)$ & $21(-1,43)$ \\
\hline $\begin{array}{l}\text { Amputation, PVD, neuropathy or } \\
\text { macroalbuminuria }\end{array}$ & $4512(45)$ & 1.7 & 0.6 & $5(1,10)$ & $2(-1,4)$ & $16(-6,38)$ \\
\hline
\end{tabular}

Numbers of events caused and prevented were estimated using the summary CANVAS Program estimates of relative risks for each outcome, but the absolute event rates are those specific to each participant subgroup

${ }^{a}$ Excluding those with amputation history

PVD, peripheral vascular disease

among those who develop diabetic foot ulcers, infection, osteomyelitis or gangrene. The current data add weight to these recommendations.

There are few additional amputation events recorded in other phase 3 and 4 randomised trials of canagliflozin vs placebo or active comparators $(n=10 / 8114$, RR $0.23,95 \%$ CI $0.06,0.89$ ), reflecting both the lower cardiovascular risk of those participants and a shorter average duration of followup [8]. Empagliflozin displayed similar rates of amputation when compared with placebo (6.5 per 1000 participant-years for both treatment groups) in EMPA-REG OUTCOME [9], with an overall RR for amputation with empagliflozin vs placebo of 1.02 (95\% CI 0.72,1.45) [10]; comparable rates in the CANVAS Program were 6.30 (active) and 3.37 (placebo) per 1000 participant-years. Recent data for ertugliflozin [7] suggest an imbalance in atraumatic lower limb amputation, with rates per 1000 participant-years in the $15 \mathrm{mg}, 5 \mathrm{mg}$ and comparator groups of 4.4, 1.6 and 0.6 across the development programme (12 events) and 5.0, 6.8 and 4.3 in the separate and ongoing cardiovascular outcome trial (61 events). Additional data for these and other SGLT2 inhibitors under investigation in large-scale trials remain undisclosed at this time. The ongoing Canagliflozin and Renal Events in Diabetes with Established Nephropathy Clinical Evaluation (CREDENCE) trial of canagliflozin among individuals with nephropathy [11] will provide valuable additional insight about the effects of canagliflozin on amputation.

In an observational analysis of the Truven United States Commercial database ( $n=63,845$ matched pairs), new users of canagliflozin were not observed to have increased risks of amputation compared with new users of non-SGLT2 glucoselowering therapies (HR 0.98 [95\% CI 0.68, 1.41]) [8]. The 
same was true in the OBSERVE-4D analysis of 142,800 new users of canagliflozin compared with other agents [12]. By contrast, data from the Department of Defense database [13] showed that individuals with type 2 diabetes and established cardiovascular disease treated with SGLT2 inhibitors (mostly canagliflozin) compared with other glucose-lowering therapies ( $n=12,629$ matched pairs) had an increased risk of amputation (HR 1.99 [95\% CI 1.12, 3.51]) directly comparable in magnitude with that observed in the CANVAS Program. A disproportionality analysis of the WHO global database of individual case safety reports (VigiBase) based upon 79 amputation events identified increased proportional reporting ratios for SGLT2 inhibitors that were significant for canagliflozin, empagliflozin and dapagliflozin [14, 15]. A registry database from Sweden and Denmark, using a propensity score matched cohort of 17,213 new users of SGLT2 inhibitors (dapagliflozin 61\%; empagliflozin 38\%; canagliflozin 1\%) and 17,213 new users of an active glucagon-like peptide-1 (GLP-1) receptor agonist demonstrated an HR for amputation of 2.32 (95\% CI 1.37, 3.91) for SGLT2 inhibitors [16].

Based primarily upon the CANVAS Program findings, the US Food and Drug Administration [17] and the European Medicines Agency [18] updated the product information of canagliflozin to reflect amputation risk. Warnings related to amputation appear in the product information for canagliflozin and ertugliflozin but not empagliflozin and dapagliflozin. The large-scale EMPA-REG OUTCOME study [19] did not initially report upon amputation risk, but retrospective analyses of the trial and the broader empagliflozin database identified no relative differences in amputation rates between individuals on active therapy and those on placebo [20]. The canagliflozin and ertugliflozin reports benefitted from data collected as part of active trial programmes, rather than retrospective investigations of the databases; whether this or unknown differences in the pharmacological actions of the compounds explains the different findings from empagliflozin is uncertain. Additional prospectively collected data for amputation will become available from ongoing large trials of these and other SGLT2 inhibitors over the next few years, and will be key to understanding whether the amputation risk is specific to particular drugs or is a class effect and whether the risk can be ameliorated through specific active management strategies.

The present report benefits from the rigorous design, conduct and analysis of the CANVAS Program, the rigorous search of the database for all possible amputation events and the careful masked adjudication of identified events. However, there was limited documentation of peripheral artery disease at baseline and incomplete recording of detailed description of the acute and chronic factors leading to each amputation. The few amputation events recorded limited the capacity to detect effects in participant subgroups and interpreting multiple tests makes interpretation of borderline significant findings difficult (e.g. the interaction of canagliflozin treatment and amputation risk with baseline antithrombotic use). Likewise, the small numbers of events weaken the conclusions about the subsets of amputation events. The absence of a clear mechanism by which canagliflozin or any other SGLT2 inhibitor might contribute to amputation also adds significant complexity to the interpretation of the findings.

In conclusion, the CANVAS Program demonstrated that canagliflozin increased the risk of amputation (mainly minor) in this study population. Anticipated risk factors for amputation, such as prior history of amputation, peripheral vascular disease and neuropathy, were identified (see Table 3 ) but no specific aetiological mechanism or at-risk subgroup for canagliflozin was identified. Despite that increased risk, however, canagliflozin showed significant protective effects against major cardiovascular events and demonstrated HRs indicative of reduction of renal complications in type 2 diabetes.

Acknowledgements The trials were sponsored by Janssen Research \& Development, LLC, and conducted as a collaboration between Janssen, an academic steering committee and an academic research organisation, George Clinical. Analyses were undertaken independently by the sponsor and George Clinical. The authors thank all investigators, study teams and participants for taking part in these studies. The authors thank the following people for their contributions to the statistical monitoring/ analyses and the protocol development, safety monitoring and operational implementation over the duration of both studies: L. Hones and L. Perry (George Clinical, Australia); S. Dunkley (Molecule2Market, Australia); T. Sun, H. Deng, G. Capuano, G. Law, J. Lind, R. Simpson, T. Barrett, E. Connell, M. Wells, J. Yee, D. Balis, F. Vercruysse, R. Oh, N. Meyers, G. Meininger and N. Rosenthal (Janssen Research \& Development, LLC, USA) and S. Bompoint and L. Billot (The George Institute, Australia). Medical writing support was provided by K. Dittmar and D. Tabor (MedErgy, USA) and was funded by Janssen Global Services, LLC. Canagliflozin has been developed by Janssen Research \& Development, LLC, in collaboration with Mitsubishi Tanabe Pharma Corporation.

Data availability Data from the CANVAS Program will be made available in the public domain via the Yale University Open Data Access Project (YODA; http://yoda.yale.edu/) once the product and relevant indication studied have been approved by regulators in Europe and the USA and the study has been completed for 18 months.

Funding The CANVAS Program trials were funded by Janssen Research $\&$ Development and done as a collaboration between the funder, an academic steering committee and an academic research organisation (George Clinical). The funder was involved in the study design, data collection, data analysis, data interpretation and writing of this report. Data analyses were done by the funder and were independently replicated and had results confirmed by a statistician at George Clinical; any discrepancies were resolved by discussion. The corresponding author had full access to all the data in the study and had final responsibility for the decision to submit for publication.

Duality of interest DRM reports receiving support from Janssen for his role as co-chair of the CANVAS Program steering committee. QL reports being a full-time employee of the George Institute for Global Health. VP reports receiving personal fees for advisory boards or scientific 
presentations from Retrophin, Janssen, Merck and Servier, serving on steering committees for trials funded by AbbVie, Boehringer Ingelheim, GlaxoSmithKline, Janssen and Pfizer and participating in scientific presentations/advisory boards with AbbVie, Astellas, AstraZeneca, Bayer, Baxter, Bristol-Myers Squibb, Boehringer Ingelheim, Durect, Eli Lilly, Gilead, GlaxoSmithKline, Novartis, Novo Nordisk, Pharmalink, Relypsa, Sanofi and Vitae, with all fees paid to his employer. KWM reports receiving grants from Afferent, Amgen, Apple Inc., AstraZeneca, Cardiva Medical, Daiichi, Ferring, Google (Verily), Johnson \& Johnson, Luitpold, Medtronic, Merck, Novartis, Sanofi, St Jude and Tenax, receiving personal fees from Ablynx, AstraZeneca, Baim Institute, Boehringer Ingelheim, Bristol-Myers Squibb, Cardiometabolic Health Congress, Elsevier, GlaxoSmithKline, Johnson \& Johnson, Medscape, Merck, Mitsubishi, Myokardia, Novartis, Oculeve, Portola, Radiometer, Springer Publishing, Theravance, University of California San Francisco and WebMD and having equity in BioPrint Fitness. DdZ reports serving on advisory boards and/or as a speaker for Bayer, Boehringer Ingelheim, Fresenius, Mundipharma and Mitsubishi-Tanabe, being a steering committee member and/or speaker for AbbVie and Janssen and serving on Data Safety and Monitoring Committees for Bayer. GF reports receiving grants from Novo Nordisk and personal fees from Janssen, Novo Nordisk, Boehringer Ingelheim and Merck Sharp \& Dohme. MD, EF, MK and ML report being fulltime employees of Janssen Research \& Development, LLC. MK reports holding stock in Johnson \& Johnson. WRH reports receiving grants from Janssen and Bayer. MN reports receiving salary support from CPC Research. BN reports receiving grants and travel costs related to presentation of data from Janssen and serving on advisory boards for Janssen, with any consultancy, honoraria or travel support paid to his institution. No other potential conflicts of interest relevant to this article are reported.

Contribution statement DRM, VP, KWM, DdZ, GF, MD, EF, MK, ML and $\mathrm{BN}$ contributed to the design and conduct of the study and the interpretation of the data. QL, WRH and MN contributed to the analysis and interpretation of data. DRM wrote the first draft of the manuscript and all authors contributed to subsequent drafts. All authors had full access to the data, made final decisions about content, vouch for the accuracy and completeness of the analyses and approved the final version for submission. DRM and BN had full access to all the data in the study and take responsibility for the integrity of the data and the accuracy of the data analysis.

Open Access This article is distributed under the terms of the Creative Commons Attribution 4.0 International License (http:// creativecommons.org/licenses/by/4.0/), which permits unrestricted use, distribution, and reproduction in any medium, provided you give appropriate credit to the original author(s) and the source, provide a link to the Creative Commons license, and indicate if changes were made.

\section{References}

1. Cefalu WT, Leiter LA, Yoon KH et al (2013) Efficacy and safety of canagliflozin versus glimepiride in patients with type 2 diabetes inadequately controlled with metformin (CANTATA-SU): 52 week results from a randomised, double-blind, phase 3 non-inferiority trial. Lancet 382(9896):941-950. https://doi.org/10.1016/S01406736(13)60683-2

2. Neal B, Perkovic V, Mahaffey KW et al (2017) Canagliflozin and cardiovascular and renal events in type 2 diabetes. N Engl J Med 377(7):644-657. https://doi.org/10.1056/NEJMoa1611925

3. Neal B, Perkovic V, de Zeeuw D et al (2013) Rationale, design, and baseline characteristics of the Canagliflozin Cardiovascular
Assessment Study (CANVAS)-a randomized placebo-controlled trial. Am Heart J 166(2):217-223 e211. https://doi.org/10.1016/j. ahj.2013.05.007

4. Neal B, Perkovic V, Matthews DR et al (2017) Rationale, design and baseline characteristics of the CANagliflozin cardioVascular Assessment Study-Renal (CANVAS-R): a randomized, placebocontrolled trial. Diabetes Obes Metab 19(3):387-393. https://doi. org/10.1111/dom.12829

5. Neal B, Perkovic V, Mahaffey KW et al (2017) Optimizing the analysis strategy for the CANVAS Program: a prespecified plan for the integrated analyses of the CANVAS and CANVAS-R trials. Diabetes Obes Metab 19(7):926-935. https://doi.org/10.1111/dom. 12924

6. Janssen Inc (2017) Product monograph - C. Available from https:// www.drugs.com/monograph/canagliflozin.html. Accessed 26 June 2018

7. STEGLATRO ${ }^{\mathrm{TM}}$ [package insert] (2017) Whitehouse Station, NJ: Merck Sharp \& Dohme Corp

8. Yuan Z, Defalco FJ, Ryan PB et al (2018) Risk of lower extremity amputations in patients with type 2 diabetes mellitus treated with SGLT2 inhibitors in the United States: a retrospective cohort study. Diabetes Obes Metab 20(3):582-589. https://doi.org/10.1111/dom. 13115

9. Inzucchi SE, Iliev H, Pfarr E, Zinman B (2018) Empagliflozin and assessment of lower-limb amputations in the EMPA-REG OUTCOME trial. Diabetes Care 41(1):e4-e5. https://doi.org/10. 2337/dc17-1551

10. Radholm K, Wu JH, Wong MG et al (2018) Effects of sodiumglucose cotransporter-2 inhibitors on cardiovascular disease, death and safety outcomes in type 2 diabetes - a systematic review. Diabetes Res Clin Pract 140:118-128. https://doi.org/10.1016/j. diabres.2018.03.027

11. Jardine MJ, Mahaffey KW, Neal B et al (2017) The Canagliflozin and Renal Endpoints in Diabetes with Established Nephropathy Clinical Evaluation (CREDENCE) study rationale, design, and baseline characteristics. Am J Nephrol 46(6):462-472. https://doi. org $/ 10.1159 / 000484633$

12. Ryan PB, Buse JB (2018) Comparative effectiveness of canagliflozin, SGLT2 inhibitors and non-SGLT2 inhibitors on the risk of hospitalization for heart failure and amputation in patients with type 2 diabetes mellitus: a real-world meta-analysis of $4 \mathrm{ob}-$ servational databases (OBSERVE-4D). Diabetes Obes Metab 20(11):2585-2597. https://doi.org/10.1111/dom.13424

13. Udell JA, Yuan Z, Rush T, Sicignano NM, Galitz M, Rosenthal N (2018) Cardiovascular outcomes and risks after initiation of a sodium glucose co-transporter 2 inhibitor: results from the EASEL population-based cohort study (Evidence for Cardiovascular Outcomes With Sodium Glucose Cotransporter 2 Inhibitors in the Real World). Circulation 137(14):1450-1459. https://doi.org/10. 1161/CIRCULATIONAHA.117.031227

14. Khouri C, Cracowski JL, Roustit M (2018) SGLT-2 inhibitors and the risk of lower-limb amputation: Is this a class effect? Diabetes Obes Metab 20(6):1531-1534. https://doi.org/10.1111/dom.13255

15. Fadini GP, Avogaro A (2017) SGLT2 inhibitors and amputations in the US FDA Adverse Event Reporting System. Lancet Diabetes Endocrinol 5(9):680-681. https://doi.org/10.1016/S2213-8587(17) 30257-7

16. Ueda P, Svanstrom H, Melbye M et al (2018) Sodium glucose cotransporter 2 inhibitors and risk of serious adverse events: nationwide register based cohort study. BMJ 363:k4365

17. U.S. Food \& Drug Administration (2017) FDA Drug Safety Communication: FDA confirms increased risk of leg and foot amputations with the diabetes medicine canagliflozin (Invokana, Invokamet, Invokamet XR). Available from https://www.fda.gov/ downloads/Drugs/DrugSafety/UCM558427.pdf. Accessed 9 August 2017 
18. European Medicines Agency (2017) PRAC assessment report. Available from http://www.ema.europa.eu/docs/en_GB/ document_library/Referrals_document/SGLT2 inhibitors Canagliflozin_20/European_Commission_final_decision/ WC500227102.pdf. Accessed 16 June 2017

19. Zinman B, Wanner C, Lachin JM et al (2015) Empagliflozin, cardiovascular outcomes, and mortality in type 2 diabetes. $\mathrm{N}$ Engl $\mathrm{J}$ Med 373(22):2117-2128. https://doi.org/10.1056/ NEJMoa1504720
20. Kohler S, Zeller C, Iliev H, Kaspers S (2017) Safety and tolerability of empagliflozin in patients with type 2 diabetes: pooled analysis of phase I-III clinical trials. Adv Ther 34(7):1707-1726. https://doi. org/10.1007/s12325-017-0573-0

Publisher's note Springer Nature remains neutral with regard to jurisdictional claims in published maps and institutional affiliations. 